\title{
Un experimento de proceso de creación dramatúrgica del actor a partir del personaje de María Magdalena
}

\section{An experiment of the actor's dramaturgical creation process based on the character of Mary Magdalene}

\section{Elisa Martins Lucas}

Doctora en Ciencias del Espectáculo por la Universidad de Sevilla. Directora de Artes Cênicas e investigadora en la Universidade Federal do Rio Grande do Sul (UFRGS). Fundadora del Grupo Capitu - elisa.lucas97@ufrgs.br http://orcid.org/0000-0003-2569-4873

\section{Resumen}

Describe un experimento teórico/práctico de proceso de creación dramatúrgica del actor cuyo objetivo era crear una dramaturgia que enfocase lo profano y lo sagrado en la figura femenina a partir del personaje bíblico-literario-legendario de María Magdalena. El proceso se sirvió de diferentes estímulos (objetos y sonidos), técnicas (improvisaciones corpóreo-vocales), trabajo de campo y estudios literarios de diversas fuentes. Como resultado preliminar se hizo una actuación consistente en fragmentos del texto aún en fase de elaboración, y muestra de las experimentaciones prácticas seguidas de un coloquio informal con el público, para recoger sus impresiones. El resultado final fue el texto $L a$ Dama de los Evangelios, que recría la trayectoria del personaje de forma poética y ficcionaliza algunas de sus tradiciones europeas. A través del experimento se pudo configurar un trabajo teatral y literario que contribuyó en la formación artístico-investigativa de la actriz/dramaturga. Demuestra que el proceso de creación dramatúrgica del actor se configura como una forma alternativa a la teoría y práctica teatrales, que permite al actor/dramaturgo dar voz a sus creaciones sin la necesidad de un texto previamente establecido.

Palabras-clave: Proceso de creación dramatúrgica del actor. Interpretación teatral. Dramaturgia. María Magdalena. Práctica escénica.

\begin{abstract}
It describes a theoretical/practical experiment of the actor's dramaturgical creation process aimed at creating a dramaturgy focused on the profane and the sacred in the female figure from the biblical-literary-legendary character of Mary Magdalene. The creative process employed different stimuli (objects and sounds), techniques (corporeal-vocal improvisations), fieldwork and literary studies from distinct sources. As a preliminary result, a performance was made using fragments of the text still under development, and a sample of the practical experimentation was presented to the public, followed by an informal colloquium to collect their impressions. The result was the text The Lady of the Gospels, which recreated the character's trajectory in a poetic way and fictionalized some of its European traditions. Through the experiment, it was possible to configure a theatrical and literary work that contributed to the investigative artistic formation of the actress/dramatist. It shows that the dramaturgical creation process of the actor is configured as an alternative to theatrical theory and practice, which allows the actor/dramatist to give voice to his creations without the need for a previously established text.
\end{abstract}

Keywords: The actor's dramaturgical creation process. Theatre performance. Dramaturgy. Mary Magdalene. Stage praxis.

Recibido: $14 / 11 / 2018$

Aceptado: $12 / 04 / 2019$ 


\section{INTRODUCCIÓN}

El proceso de creación dramatúrgica del actor consiste en prácticas donde el actor actúa también como autor, interfiriendo en la creación dramatúrgica de la obra. Ellas invierten el orden convencional del teatro: en vez de partir de un texto para construir el personaje, actores y directores, trabajando de forma práctica, artesanal y, muchas veces intuitiva, mezclan técnicas y ensayan distintas posibilidades para construir el guion.

En el panorama teatral internacional se ha observado que las investigaciones escénicas de Eugenio Barba (Dinamarca), así como las creaciones del Théâtre du Soleil dirigidas por Ariane Mnouchkine (Francia) y los textos de Dario Fo (Italia) podrían ser considerados ejemplos de procesos de creación dramatúrgica del actor, una vez que el actor posee un grado importante de autonomía en la creación dramatúrgica. En Brasil se encuentran prácticas semejantes en el Grupo Lume - Núcleo Interdisciplinar de Pesquisas Teatrais da Unicamp (Campinas-SP), Teatro da Vertigem (SP), Amok Teatro (RJ) y Tribo de Atuadores Ói Nóis Aqui Traveiz (RS), cada uno con sus particularidades. Como ejemplos de espectáculos oriundos de tales procesos se pueden citar: Judith (Odin Teatret, Dinamarca 1987), Solos em Cena (Grupo Tear, Porto Alegre, 2001), Carta de um Pirata: Uma comedia inconformada (Vinicius Piedade, São Paulo, 2003), Identidade (Vinicius Piedade, São Paulo, 2012) y O Incansável Dom Quixote (Maksin Oliveira, Rio de Janeiro, 2013).

Con el fin de sistematizar una metodología del proceso de creación dramatúrgica del actor, la actriz/dramaturga Elisa Lucas se propuso a desarrollar un experimento teórico/práctico del proceso, trabajando en colaboración con un equipo de expertos y sirviéndose de distintos estímulos, para diseñar una dramaturgia de nueva creación en torno a María Madalena, figura consagrada por la literatura y el imaginario popular, teniendo además en cuenta los aspectos sacro y profano del personaje. El experimento ${ }^{1}$ fue la primera etapa de la investigación para la tesis doctoral Lo Profano y lo Sagrado en el Proceso de creación dramatúrgica del actor a partir del personaje de María Magdalena. Interrelación entre teoría y praxis escénica ${ }^{2}$ (ELIADE, 2016) realizada en el Doctorado en Ciencias del Espectáculo de la Universidad de Sevilla, bajo la dirección de la Doctora María Concepción Pérez Pérez.

\footnotetext{
${ }^{1}$ El experimento recibió la Ayuda a Procesos de Creación Dramatúrgica en Residencia de Iberescena 2010/2011, del Fondo Iberoamericano de Ayuda Iberescena.

${ }^{2}$ Investigación realizada con Beca de la Coordinación de Perfeccionamiento de Personal de Nivel Superior - Brasil.
} 
Se eligió al personaje de María Magdalena porque la figura bíblico-literaria-legendaria se prestaba a ser interpretada desde diversos ángulos. Venerada oficialmente como Santa María Magdalena por las iglesias católica romana, ortodoxa, ortodoxa oriental, anglicana y luterana, con templos en todo el mundo dedicados a su figura, es un personaje que, a lo largo de los siglos, adquirió gran importancia en el imaginario popular cristiano occidental a partir de leyendas y tradiciones relacionadas con su nombre.

Los aspectos sacro y profano se enfocaron desde la perspectiva propuesta por Eliade (1998, p. 17), que considera lo sagrado como la principal experiencia del hombre religioso, y lo define como todo aquello que se opone a lo profano: "[...] lo sagrado y lo profano constituyen dos modalidades de estar en el mundo, dos situaciones existenciales asumidas por el hombre a lo largo de su historia". A estos aspectos se les concedieron un tratamiento puramente escénico, sin aspirar a posicionamientos filosóficos o teológicos de ningún tipo. A continuación, se relatan y se presentan las fases del experimento.

El experimento fue desarrollado siguiendo una serie de fases, establecidas a partir de la experiencia de la actriz/dramaturga en investigaciones anteriores. Tras la elección del personaje, se procedió se a un estudio del mismo en diversas fuentes, incluyendo trabajo de campo en la Semana Santa de Sevilla, visita y registro fotográfico a la Parroise de la Madeleine (Paris), consulta a fuentes bibliográficas, folclóricas e pictóricas, procedentes de diferentes tradiciones, que sirvieron para hacer el embasamiento de la selección de situaciones del personaje y definir los objetivos que lo mismo pretendería alcanzar a lo largo de la dramaturgia a ser creada. A continuación, se hizo la selección de estímulos para la creación dramatúrgica, en la forma de materiales como objetos y sonidos con los cuales la actriz iba a interactuar. Para Brook (2000, p. 38), "el actor posee un extraordinario potencial para crear vínculos entre su imaginación y la del público, haciendo con que un objeto banal se pueda transformar en un objeto mágico." 3

Para cada una de las situaciones elegidas con los diferentes estímulos seleccionados, fueron realizadas experimentaciones a través de improvisaciones corpóreo-vocales, registradas textualmente. Según Panisson (2016, p. 49):

\footnotetext{
${ }^{3}$ Traducido del portugués al español por la autora.
} 
Para el actor, la técnica de la improvisación es un canal de expresión de sus ambiciones y sus impulsos creativos, que le posibilita sorprender y desfrutar de la oportunidad de ejercitar su potencial imaginativo y hacer valer a su cuerpo como territorio de creación ${ }^{4}$.

A partir de las improvisaciones fue trazado un primer esbozo de guión, que fue perfeccionado a través de ficcionalización ${ }^{5}$ de las lagunas encontradas en la historia del personaje, como forma de convertirlo en una serie de escenas que tuviesen principio, medio e fin. Luego se hicieron definiciones objetivas en la dramaturgia, como la elección del título de la obra y de los personajes que figurarían junto de la protagonista.

\section{ESTUDIO DEL PERSONAJE}

Los dos primeros meses se dedicaron al estudio del personaje en fuentes bibliográficas, folclóricas y pictóricas. Se analizaron los relatos evangélicos (Evangelios: Marcos, Lucas, Mateo y Juan), leyendas medievales (Apócrifos y Leyenda Dorada), y algunas novelas modernas que mencionan a María Magdalena. En paralelo, la actriz/dramaturga asistió a clases de teología en la Universidad de Sevilla y entrevistó al Profesor Rafael Portillo García, experto en temas religiosos y literarios. También realizó documentación de las imágenes de María Magdalena en la Semana Santa de Sevilla, para lo cual asistió a ensayos y procesiones de hermandades, y fotografió los llamados $\operatorname{pasos}^{6}$ donde figuraba María Magdalena, con objeto de estudiar el enfoque que desde la religiosidad popular sevillana se ofrecía de este personaje. Además, visitó y fotografió a la Parroise de la Madeleine (Paris).

\subsection{María Magdalena en la semana santa de Sevilla}

En la Semana Santa de Sevilla, considerada Fiesta Mayor de la ciudad, es María Magdalena, después de la Virgen María, el personaje femenino que más veces figura en los pasos. Actualmente María Magdalena está presente en trece misterios de la Semana Santa sevillana, apareciendo fundamentalmente a los pies del Crucificado, con frecuencia arrodillada en posición de oración y casi siempre Ilorando (Figura 01). Nunca aparece sola. En muchos pasos el personaje da la espalda al espectador, porque mira hacia Cristo. Algunos hermanos de las cofradías a los que se pudo

\footnotetext{
${ }^{4}$ Traducido del portugués al español por la autora.

${ }^{5}$ Aunque la palabra "ficcionalización" no exista en el diccionario de la RAE (Real Academia Española), es un término de uso frecuente entre dramaturgos e investigadores de estudios literarios y crítica literária.

${ }^{6}$ De inspiración barroca, un paso es una plataforma llevada por hombres, sobre la que figuran las imágenes o estatuas de los personajes de la Pasión de Jesucristo.
} 
entrevistar informalmente, seguían considerando a la Magdalena una prostituta arrepentida; quizá por eso en las imágenes aparece como una mujer de pelo largo y suelto, y nunca lleva velo o toca, mientras que todos los demás personajes femeninos llevan la cabeza cubierta. Otra característica que llama la atención es que algunas imágenes incorporan un cáliz (Figura 02), con el que, según la tradición sevillana, María Magdalena recoge la sangre de Cristo.

Figura 01- Imagen de la izquierda: en el paso de la hermandad de La Lanzada, María Magdalena está arrodillada bajo el crucificado en posición de oración. Imagen de la derecha: María Magdalena llora en el paso de la hermandad La Trinidad.
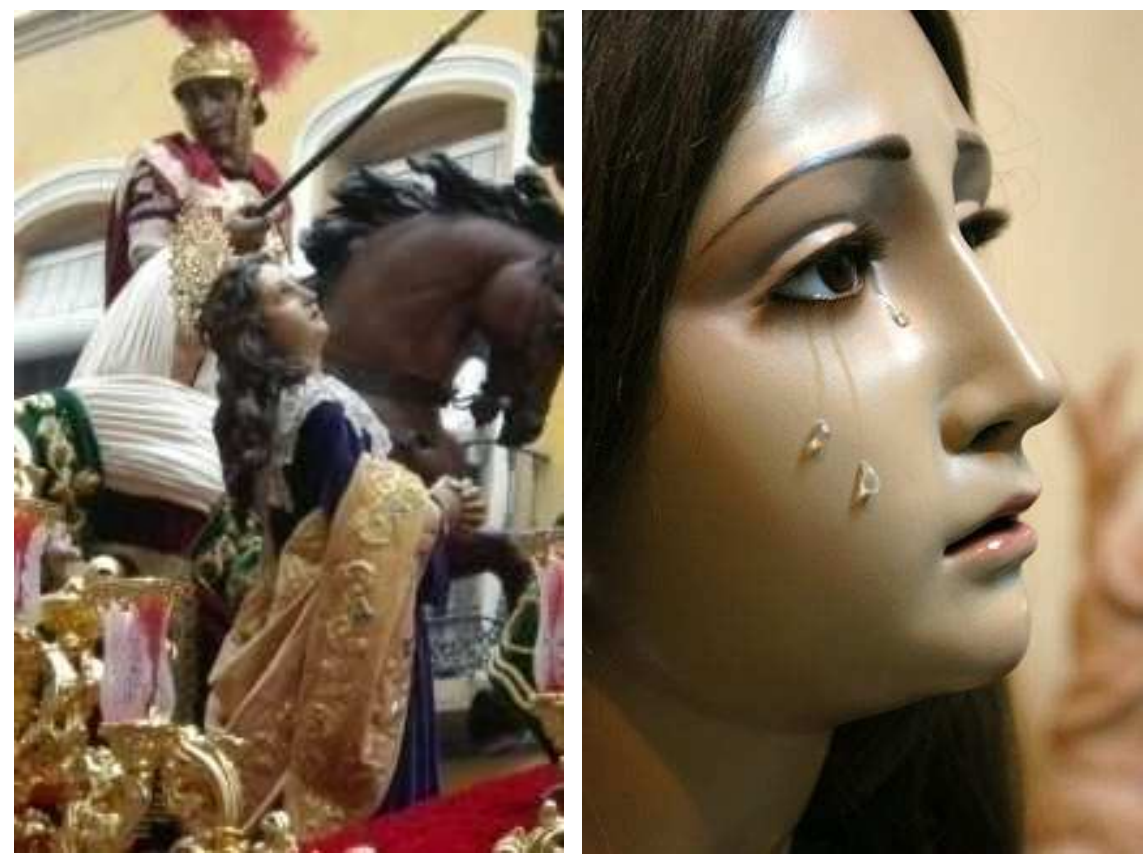

Fuente: de la autora (2011).

Figura 02 - En detalle del Paso Del Valle, María Magdalena, sin velo, con el cáliz para recoger la sangre de Cristo.

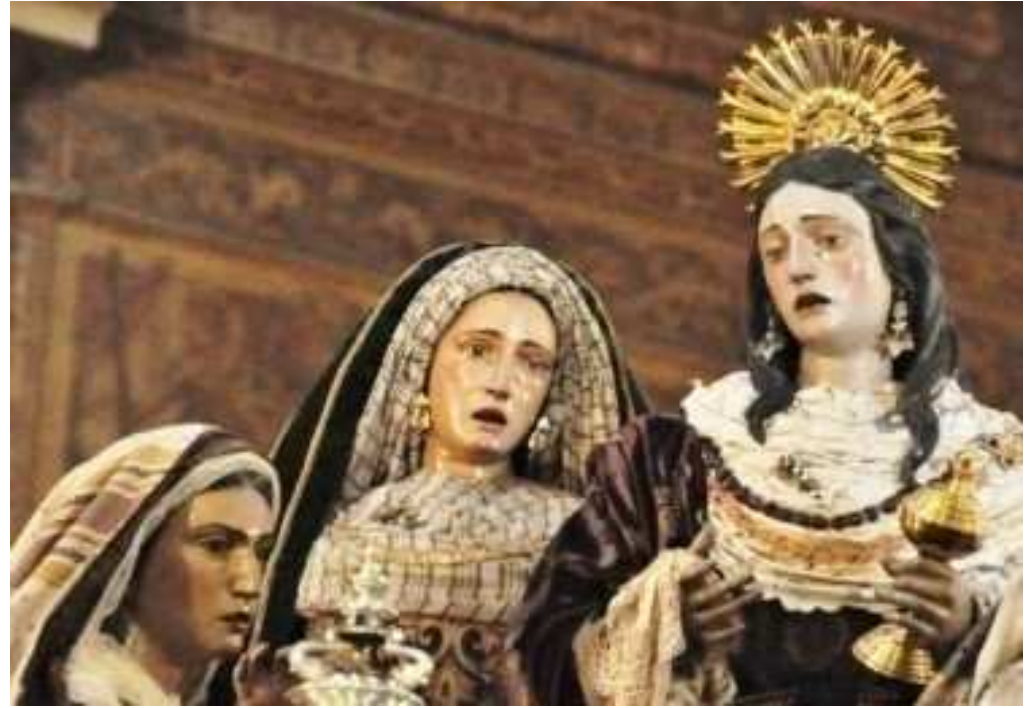

Fuente: de la autora (2011). 


\subsection{María Magdalena en Paris}

La Parroise de la Madeleine (Figura 03) presenta María Magdalena como la mujer que introdujo el cristianismo en Europa cuando, según la leyenda provenzal relatada en la Leyenda dorada (VORAGINE, 1990), huyó al sur de Francia tras la muerte de Jesucristo. María Magdalena tiene muchos devotos en Francia, donde se la responsabiliza de la conversión al cristianismo de Francia y otros países europeos.

Figura 03 - Parroise de la Madeleine (Paris).

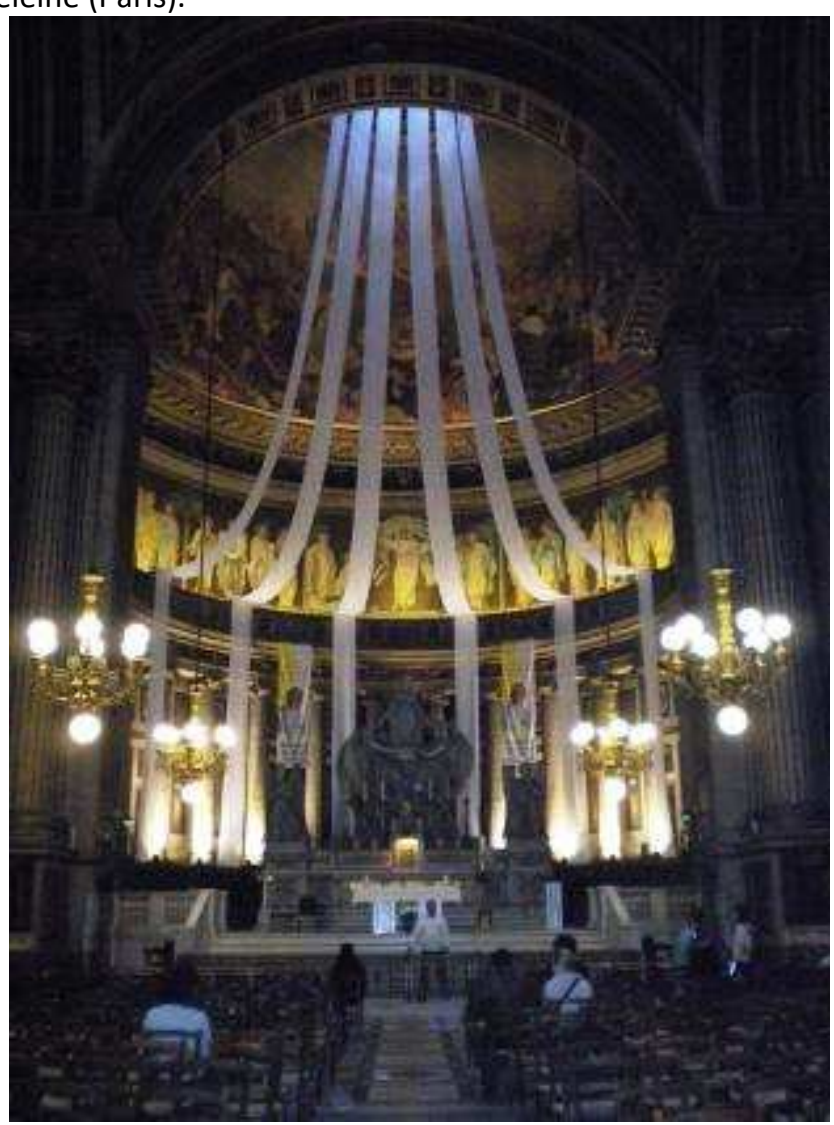

Fuente: de la autora (2011).

\section{ELECCIÓN DE SITUACIONES DEL PERSONAJE}

Partiendo del estudio del personaje, se seleccionaron momentos de su vida o situaciones, procedentes de las tradiciones evangélica, eclesiástica, legendaria o pictórica, e fueron clasificadas como situaciones en la cuales se podría enfocar aspectos profanos o sacros con relación al personaje.

Aspectos profanos: 
a) Los Siete Demonios de María Magdalena, en alusión a los relatos evangélicos: “El primer día de la semana por la mañana resucitó Jesús y se apareció a María Magdalena, de la que había expulsado siete demonios" (BIBLIA, Marcos, 16, 9, 2008d).

b) Supuesta ansia incontrolable, gula y deseo sexual de María Magdalena, que serían una especie de hambre de todo, en alusión a la homilía XXXIII del papa Gregorio I Magno: “¿Y qué significan estos siete demonios sino todos los vicios?" (MAGNO, 1958, p. 704).

c) María Magdalena como si fuera la mujer sorprendida en adulterio: El primer contacto de María Magdalena con Jesús podría ocurrir en la escena de la lapidación, en alusión al pasaje bíblico del Evangelio de San Juan (BIBLIA, Juan, 8, 1-11, 2008b).

Aspectos sacros:

a) María Magdalena como una mirrófora (una iniciada en las artes de ungir a los muertos), en alusión a Hipólito de Roma (c.170-235), citado por Barbas (2008, p. 87) cuando llama "apóstoles de los apóstoles" a las mirróforas (grupo de santas mujeres que acompañan a María Magdalena al sepulcro con aceites y perfumes para ungir a Cristo muerto).

b) El episodio conocido como Noli me tangere, de acuerdo con el Evangelio de San Juan: (BIBLIA, Juan, 20, 1-18, 2008b). A partir de este relato, la actriz/dramaturga pretendía explotar la sorpresa / deslumbramiento / éxtasis de María Magdalena al ver a Cristo resucitado.

Se trabajó además con situaciones fruto de la imaginación de la actriz/dramaturga:

a) María Magdalena como chica que creció presa dentro de una torre, La Torre de Magdala (ya que estaba poseída por los siete demonios y no debía entrar en contacto con otras personas), relacionando también la torre con el sustantivo Magdala, ya que: "La palabra Magdala significa torre, castillo" (DUBY, 1995, p. 44). Los padres podrían haber escondido a la Magdalena en la torre cuando todavía era niña, por miedo a lo que pudiera hacer cuando fuera mayor.

b) El sexo, como lo profano y prohibido, frente al deseo, como algo sagrado. Interpretación del placer como una dádiva de Dios.

c) Posible hambre y ansia de conocimiento por parte de María Magdalena. Su supuesta prostitución podría ser el resultado de ese deseo de saber, ya que en su tiempo las mujeres no sabían leer, y al no conocer las palabras, no tenían acceso al estudio. Para trabajar esa situación la actriz/dramaturga se cuestionó: "Si María Magdalena tiene hambre de saber, ella debería haber tenido contacto con el saber de alguna forma" (LUCAS, 2011, p. 4). A partir de esto añadió esa 
situación, que durante el proceso se iría convirtiendo en parte del texto dramatúrgico. Se contaba que, mientras la Magdalena crecía en la torre: "El padre subía a su habitación y le leía fragmentos del libro sagrado" (LUCAS, 2012, p. 67). De esta forma, María Magdalena habría tenido contacto con las escrituras sagradas y eso justificaría su deseo de sabiduría.

d) Las supuestas orgías de la poseída, ya que María Magdalena fue considerada poseída y prostituta.

e) Salomé y su danza, según las ideas de Jean-Yves Leloup (2004, p. 28): "Salomé, filha de Herodíades, foi ela quem deu à Maria o gosto pela dança, bijuterias e festas suntuosas". Siguiendo a Leloup (2004), la actriz/dramaturga decidió trabajar con el personaje de Salomé con la idea de que fuera la única amiga de María Magdalena, de modo que esto facilitara la introducción de una segunda figura femenina en el texto. Salomé saldría a las calles, mientras que la Magdalena, como sufría estados de "posesión", se quedaría encerrada en la torre durante toda su infancia. Podría ser Salomé quien describiera a María Magdalena la naturaleza del mundo fuera de la Torre de Magdala. También serviría para hablarle de Jesucristo, de modo que María Magdalena empezara a conocerlo a través de los relatos de su amiga. Por otro lado, la danza de Salomé podría funcionar como una imagen de la dualidad propia de cada persona, en la que se unen lo bueno y lo malo, lo sagrado y lo profano. La danza como metáfora, además, permitiría a la actriz/dramaturga explotar el deseo de libertad de María Magdalena (deseo de salir de la torre donde está encerrada).

f) La primera vez que María Magdalena sale de la torre y ve la ciudad de Magdala.

\section{POSIBLES OBJETIVOS DEL PERSONAJE}

A partir del material estudiado y de las situaciones elegidas, se trazaron posibles objetivos que María Magdalena pretendería alcanzar a lo largo de la dramaturgia:
a) Confesarse;
b) Contar su historia: su hambre, sus ansias y su soledad;
c) Salir de la Torre de Magdala;
d) Saciar el hambre;
e) Obtener la curación de sus posesiones;
f) Entregarse al placer sagrado de los cuerpos;
g) Obtener conocimiento; 
h) Salvar a Cristo;

i) Huir con Cristo;

J) Anunciar la doctrina de Jesucristo y ser escuchada.

\section{ESTÍMULOS PARA LA CREACIÓN}

La actriz/dramaturga hizo acopio de materiales que sirvieron de estímulos para la creación dramatúrgica: Música de Semana Santa y de las culturas árabe y egipcia; jarros, en alusión a uno de los atributos del personaje, perfumes e incienso, hojas representando a papiros; velas; telas; arena; hierba seca, representado a mirra, comida (frutas y pasteles).

\section{EXPERIMENTACIONES}

A través de improvisaciones corpóreo-vocales, se investigaron las situaciones elegidas, con el apoyo de los materiales, músicas, referencias de lecturas y propuestas imaginadas. Durante las improvisaciones, la actriz/dramaturga realizó acciones físicas y vocales completas, explorando distintas atmósferas, intentando transcenderlas sin perder la coherencia, dejando su imaginario libre para crear asociaciones inesperadas que contribuyesen a la creación de textos/escenas y buscando, sobre todo, sorprenderse a sí misma con reacciones espontáneas. Pavis (2003, p. 50) propone que cuanto más se transformen las emociones en acciones o actitudes físicas, más se liberará el actor de lo psicológico. Las melodías seleccionadas también sirvieron de estímulo en las improvisaciones, ya que según Pavis (2003, p. 133): “La música, en general, y particularmente en la escena, tiene una función ora integradora, ora desintegradora para el espectáculo y el ego de los personajes"7.

Para cada experimentación, eran producidos materiales textuales. A partir de improvisaciones con telas sobre temas como las supuestas orgías de la poseída; el sexo como algo profano y prohibido; el ansia incontrolable, la gula y el deseo sexual de María Magdalena y el hambre de conocimiento de la Magdalena, se creó el siguiente texto:

En la Torre de Magdala, cuando la poseída se convierte en meretriz y cambia placeres por conocimiento, todas las almas se encuentran y los cuerpos resplandecen. La ley suprema es el éxtasis que derrite cuerpos en sudor, perfumes y olor de esperma. Los arcángeles se inclinan con la sonrisa de las miradas maliciosas. Y las vírgenes se entregan en el sacrificio del propio placer (LUCAS, 2011, p. 9).

\footnotetext{
${ }^{7}$ El texto ha sido traducido del portugués al español por la autora.
} 
Trabajando dicho texto, fue creada una coreografía con una tela, para estilizar y sugerir los movimientos de una relación sexual (Figuras 04, 05, 06). La coreografía formaría parte de las acotaciones del texto:

Música. La actriz coge las dos puntas de la tela roja y camina hacia los espectadores en una especie de celebración del propio cuerpo. Se sienta en el suelo. Abre las piernas, insinuándose, y amarra las cuatro puntas de la tela a las cuatro extremidades de su cuerpo, como si estuviera dispuesta a empezar un acto sadomasoquista. Con la tela empieza una coreografía sugiriendo movimientos de una relación sexual. Esa coreografía puede ser construida por la actriz a partir de grabados y figuras de María Magdalena. Tras dichos movimientos, se cubre con la tela y empieza a masturbarse, no se ve su rostro (LUCAS, 2011, p. 9).

Figura 04 - Elisa Lucas en Lo profano y lo sagrado. Magdalena celebra el propio cuerpo, ofrece su cuerpo a los espectadores y amarra las puntas de la tela a las extremidades de su cuerpo.
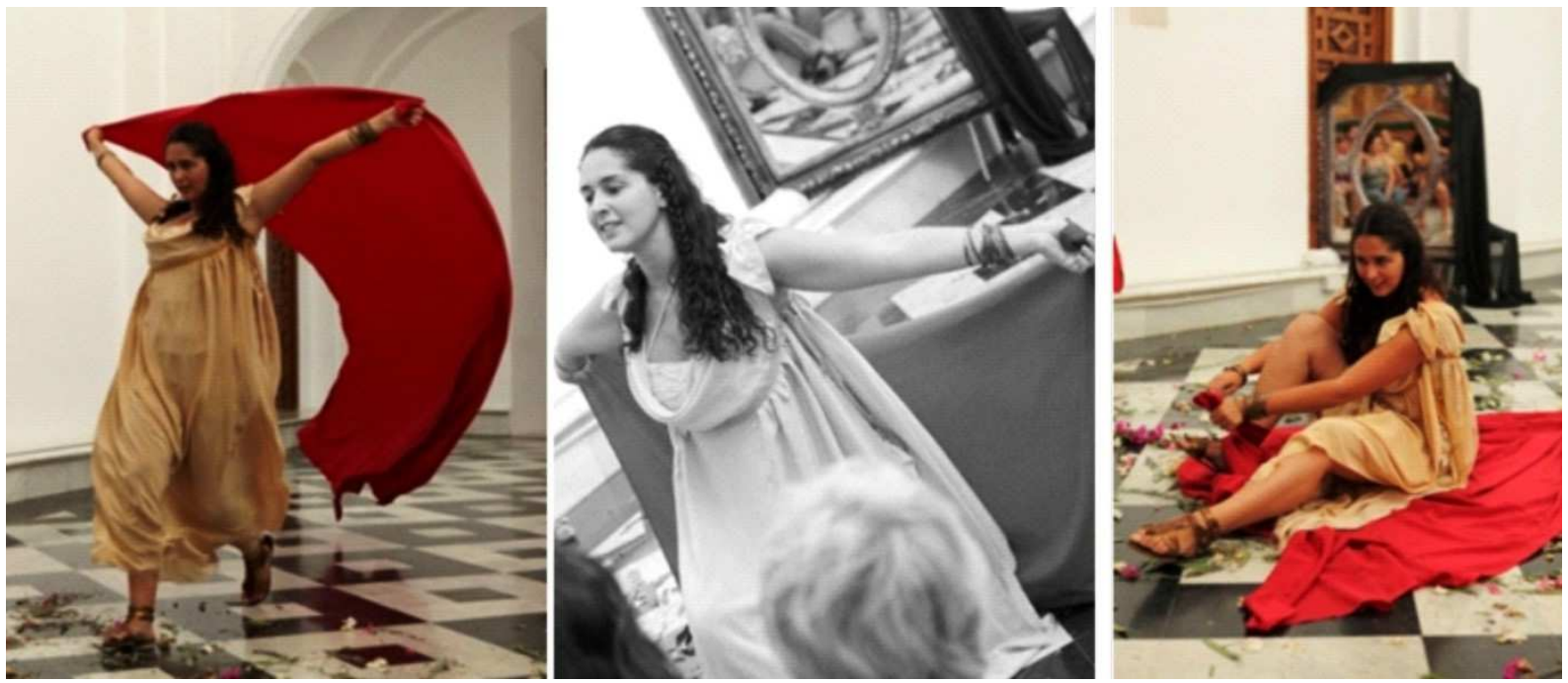

Fuente: Foto de Florentino Yamuza (2011) en Lucas (2016). 
Figura 05 - Elisa Lucas en Lo profano y lo sagrado en la figura femenina. Coreografía sugiere movimientos de una relación sexual.

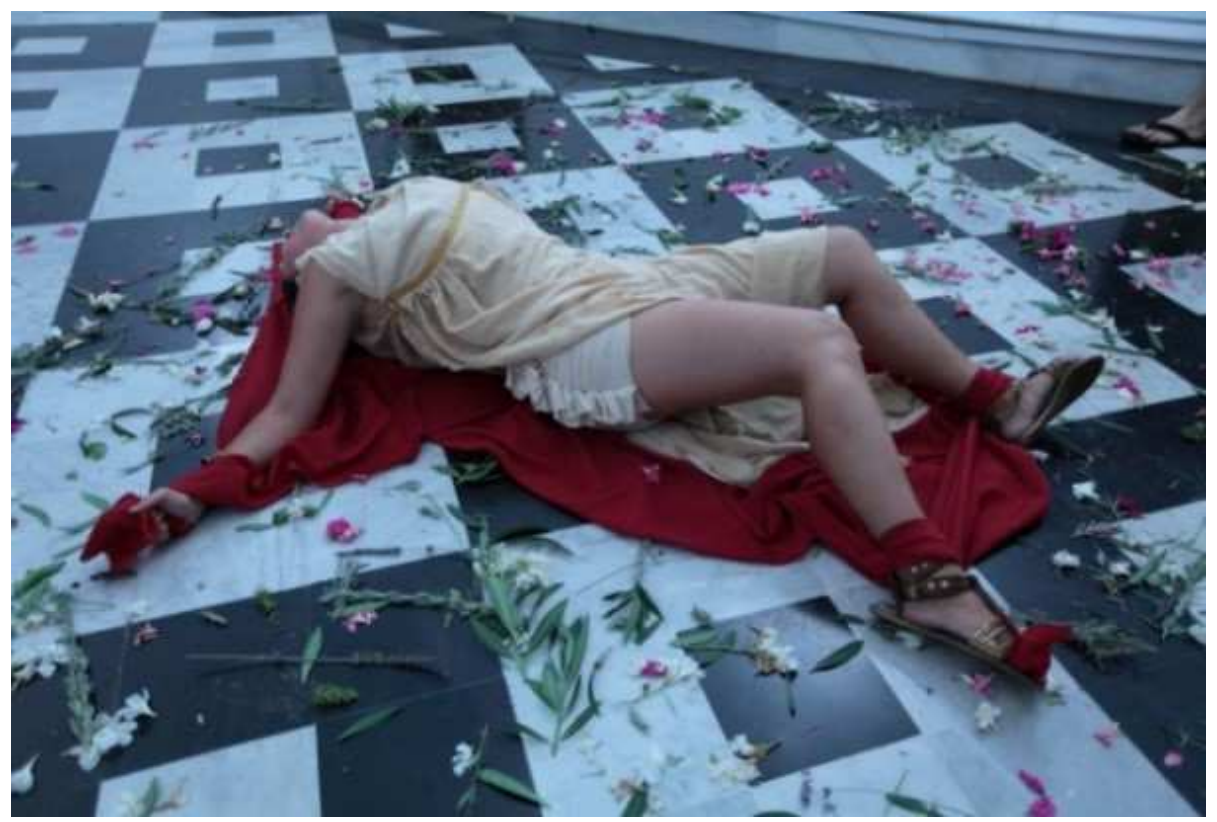

Fuente: Foto de Florentino Yamuza (2011) en Lucas (2016).

Figura 06 - Elisa Lucas en Lo profano y lo sagrado. El placer como algo prohibido: Magdalena se masturba cubierta por la tela.

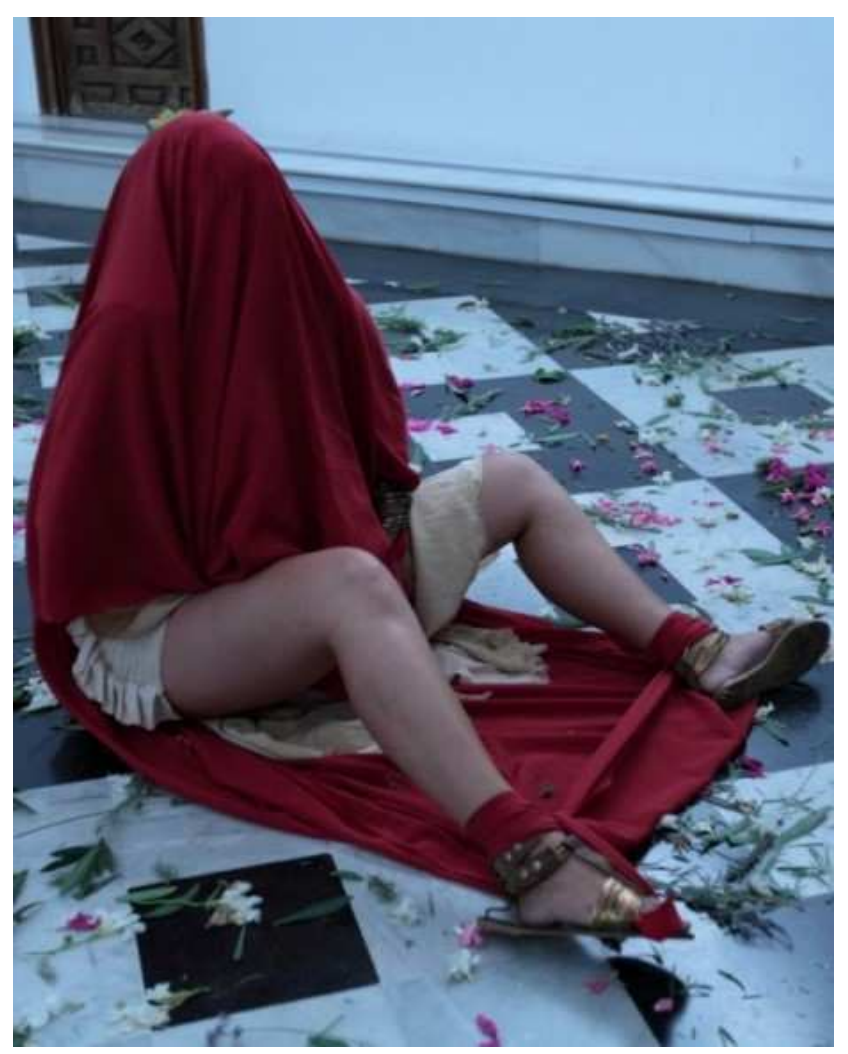

Fuente: Foto de Florentino Yamuza (2011) en Lucas (2016). 
De las improvisaciones sobre el tema del ansia incontrolable, gula y deseo sexual de María Magdalena, resultó el siguiente texto, al que acompañan las notas tomadas durante el proceso:

\begin{abstract}
MAGDALENA $^{8}$ : De repente, todos los invitados se van marchando, hasta quedarme completamente sola (sentimiento de vacio). Entonces me empieza a entrar hambre, un hambre incontrolable (Se pone a comer desesperadamente. Saca alimentos de algún sitio) se apodera de mí. Abro mi cuerpo, los oídos, la boca, para morder, ingerir, digerir, coger, sorprender, impregnarme de todo cuanto pueda: placer, éxtasis, conocimiento, descubrimientos. Tengo angustia, y no tengo calma ni sosiego. La intento parar, te lo juro, pero no lo consigo. (Empieza a vomitar y acaba presentando un estado lamentable). Intento parar, enfriar mi sangre para que las venas no me sigan quemando. (Parece comportarse cada vez más como una posesa.) Intento contener mis gestos, la mirada, las palabras que salen de mi boca, me obstino en atrapar todo aquello que ya se me escapa, me abandona. Estoy llena de mí misma y vacía de todo el resto. Soy la mujer de mi vida. Y sigo queriendo. Lo quiero todo y no doy nada. $\mathrm{Y}$ si lo doy es para recibir más. (Vuelve a comer, a masturbarse, pero con menos intensidad que antes). Entonces siento el cuerpo pesado de comida y de sexo (NOTA: QUIZÁS AGREGAR MÁS PECADOS AQUÍ) (LUCAS, 2011, p. 10).
\end{abstract}

Para trabajar con el personaje de Salomé, la actriz buscó modular su voz y peso corporal para conseguir diferenciar a Salomé de la Magdalena. Durante las improvisaciones de María Magdalena y Salomé, se crearon los siguientes textos, a partir de los cuales, la actriz/dramaturga definió que Juan Bautista sería otro personaje más en la obra:

\begin{abstract}
MAGDALENA: (Charla con Salomé. La actriz actúa sola frente a un espejo, que refleja el rostro de Salomé. La Magdalena mira hacia la ventana, como si hubiera una manifestación) Mira, Salomé, los profetas vuelven una vez más a gritar por las calles. Ahora es un tal Juan, a quien llaman El Bautista. ¿Qué quiere decir Juan con sus amenazas? ¿Qué estará anunciando en realidad?: Os bautizo con agua; el que viene después de mí os va a bautizar con fuego. (María Magdalena se quema, podría estar encendiendo incienso, ¿tal vez una vela?). ¿Y el otro, será un brujo? (La actriz mira hacia el espejo e interpreta el papel de Salomé).

SALOMÉ: Del otro no sé nada. Quizás sea un mago. Hace trucos, transforma agua en vino, y en buen vino. ¡Y además bebe! La gente se pone inmediatamente a favor o en contra. Hay quien dice que es un impostor. Juan Bautista dice que es el Mesías. ¡Pero lo que está claro es que el Bautista es un animal salvaje! ¿Te han dicho ya cómo es? Se viste con piel de camello y se alimenta de miel silvestre. Debe oler a animal podrido. No canta, sino que grita. No sabe bailar, el pobre. ¿Pero sabes que su fuerza animal me intriga y me atrae? (LUCAS, 2011, p. 12).
\end{abstract}

Para dotar de mayor protagonismo al personaje de Salomé, la actriz/dramaturga se propuso transgredir la historia bíblica. Haciendo uso de la libertad propia del autor, se imaginó a una Salomé que se siente atraída e hipnotizada, aunque también temerosa, de Juan Bautista y de su popularidad entre los devotos. En este sentido, la actriz/dramaturga siguió los pasos de Wilde

\footnotetext{
${ }^{8}$ En el texto La dama de los Evangelios, por una cuestión de estilo, en algunos pasajes, la actriz/dramaturga se refiere a María Magdalena solamente como "Magdalena".
} 
(2003), quien en su famosa pieza dramática Salomé ya había expresado explícitamente el deseo del personaje por la figura del Bautista. Todo ello sin incluir en el drama a su madre, Herodías, quien según el relato evangélico de San Mateo habría aconsejado a su hija que pidiera la cabeza de Juan Bautista (BIBLIA, Mateo, 14, 1-8, 2008a). De ese modo, se pretendió explotar el contraste entre la devoción a la carne, personificada en Salomé y su danza, y la devoción espiritual a un único Dios (como principio del cristianismo), personificada en el Bautista. Será entonces Salomé quien de motu proprio pida la cabeza del profeta, tras haberlo intentado seducir y haber sido rechazada por él.

\section{PRIMER ESBOZO DE GUIÓN Y DEFINICIONES OBJETIVAS EN LA DRAMATURGIA}

A partir de las improvisaciones, se trazó un primer esbozo de guión. Se seleccionaron los personajes que figurarían en la obra aparte de la propia María Magdalena. Además, en el curso de las experimentaciones realizadas, se hizo balance de todo el material escénico conseguido hasta el momento para convertirlo en una serie de escenas que tuviesen principio, medio y fin, de acuerdo con el esbozo de guión.

Se escogió el título de La Dama de los Evangelios para un monólogo donde se contaría la historia de María Magdalena mediante un texto narrado e interpretado por una actriz. A María Magdalena se la menciona por vez primera en los Evangelios, y por ello parecía oportuno aludir a esa fuente. Al mismo tiempo, tanto la tradición eclesial como las propias leyendas inciden en su papel de prostituta. De ahí que el título La dama de los Evangelios haya parecido el idóneo, ya que alude a la primera fuente literaria y, a la vez, incluye el sustantivo "dama" que, en cierto modo, se parece a "madama" y, como tal, podría sugerir esa otra faceta del personaje.

\section{RESULTADOS PRELIMINARES}

Al final del quinto mes se realizó Lo profano y lo sagrado en la figura femenina ${ }^{9}$ (Figura 07), una actuación consistente en fragmentos del texto, aún en fase de elaboración, y muestra de las experimentaciones prácticas. El acto-función tuvo lugar en la capilla de afuera del Monasterio Santa

\footnotetext{
${ }^{9}$ Ficha técnica - Narradores: María Magdalena y Juan Bautista. Salomé: Elisa Lucas. Figuración de entrada: Ángela Yamuza Blanco. Asesoría de textos: María Jesús Bajo Martínez y Rafael Portillo García. Asesor de Producción: Florentino Yamuza Andrés. Arte Gráfica: Paulo Ramalho. Traje: Virginia Serna y Curso 2011 de Vestuario de Escénica Técnica Sevilla. En colaboración con: Centro de Documentación de las Artes Escénicas de Andalucía; Agencia Andaluza de Instituciones Culturales; Centro de Estudios Escénicos de Andalucía; Programa de Estudios Técnicos; Escénica Técnica Sevilla; Ramón Bocanegra; Compañía la Tarasca y Centro Andaluz de Arte Contemporáneo.
} 
María de las Cuevas (Sevilla). Tras la representación hubo un coloquio informal con el público, para recoger sus impresiones. La experiencia sirvió para investigar la relación actor/espectador según el esquema propuesto en la dramaturgia, así como para intercambiar impresiones entre la actriz/dramaturga y los espectadores tras la representación.

Figura 07 - Cartel promocional de Lo profano y lo sagrado en la figura femenina.

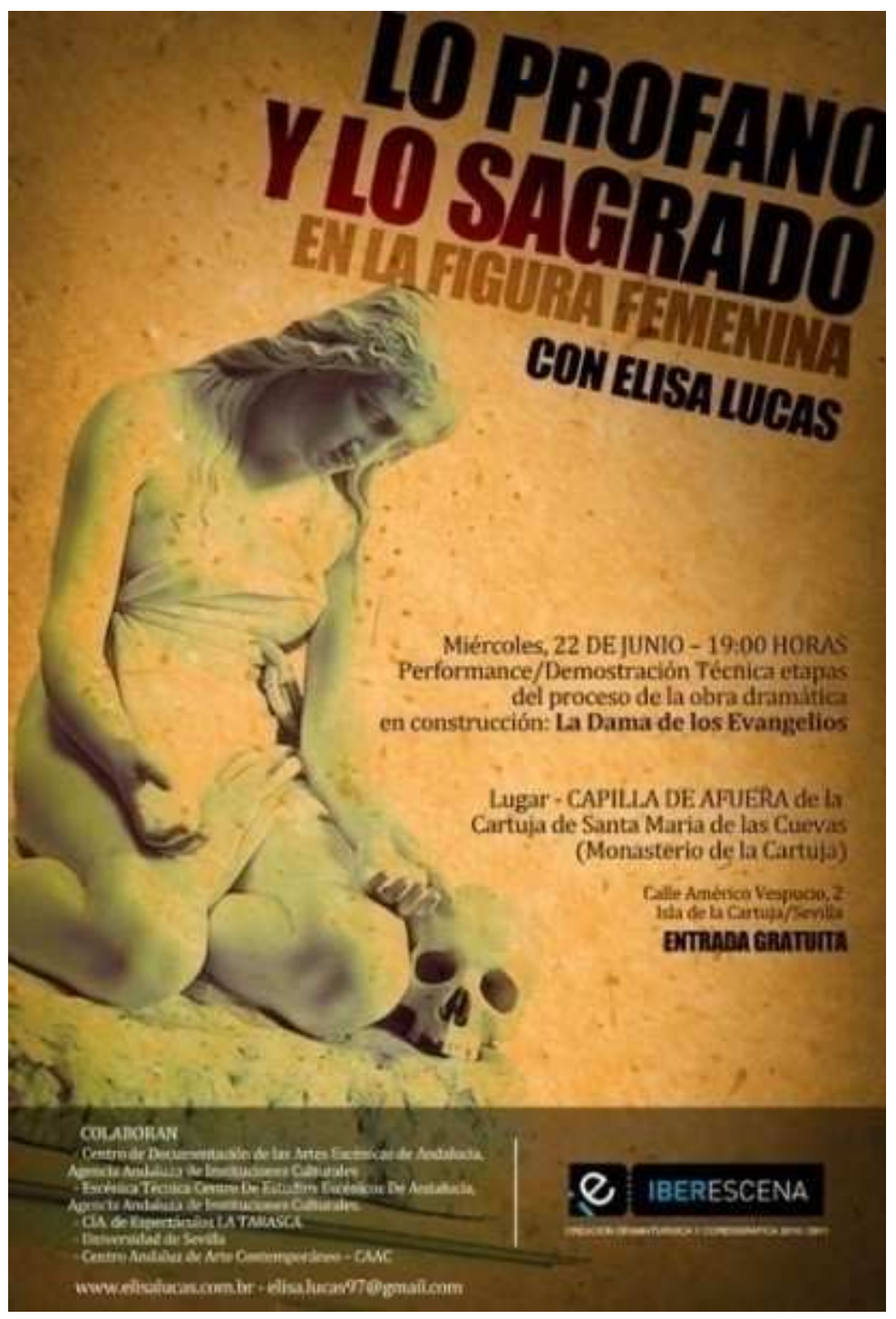

Fuente: Lucas (2016).

\section{FICCIONALIZACIÓN DE LA HISTORIA DE MARÍA MAGDALENA}

En este punto del proceso, la actriz/dramaturga recibió indicaciones presenciales del dramaturgo y director brasileño Luiz Valcazaras para la finalización del guion. Se prestó a partir de 
ese momento gran atención a la fragmentación temporal del texto con el objeto de enriquecer la dramaturgia. Se realizaron cortes y se fue alterando el guion, al tiempo que se fue separando cuidadosamente el texto lo narrado en primera persona (María Magdalena) de lo contado en tercera persona por una Narradora. Se buscó dar más cuerpo a la historia de María Magdalena, trabajando más el aspecto ficticio, aunque tratase cuestiones que contradijesen los relatos evangélicos.

El nombre de "María Magdalena", que aparece en cuatro episodios de la vida de Jesucristo (predicación, crucifixión y muerte, entierro y resurrección), se menciona un total de doce veces en los cuatro Evangelios canónicos. Ninguno de ellos aporta datos sobre edad, estado civil, familia o historia. Pero el nombre sugiere que provenía de Magdala, localidad que aún hoy existe, y que dista 200 km de Jerusalén, en la orilla occidental del Mar de Galilea, conocida por la pesca y salazón. Para recontar su historia, se hizo necesario rellenar dicha laguna a través de la ficcionalización de momentos pretéritos de su vida, tomando por base narrativas legendarias y tradiciones.

La actriz/dramaturga partió de la dramaturgia que tenía hasta el momento, y al ver las lagunas que quedaban sobre la historia de la protagonista en el texto, pasó a rellenarlas con su imaginación. Para ello, se realizó el ejercicio de crear una especie de línea cronológica ficticia de la vida de María Magdalena (Tabla 1) con los acontecimientos/fases más importantes de su vida y los distintos objetivos del personaje en cada fase. Dicha línea cronológica ficticia funcionó como un condensado actancial que contenía los núcleos generadores de los conflictos dramáticos relacionados con el personaje y, consecuentemente, con su acción dramática.

Tabla 01 - Línea cronológica ficticia de la vida de María Magdalena.

\begin{tabular}{|c|l|l|}
\hline Edad & \multicolumn{1}{|c|}{ Acontecimientos fundamentales de la vida de María Magdalena } & \multicolumn{1}{c|}{ Objetivo } \\
\hline $\mathbf{0 7}$ & Tiene visiones. Es poseída por 1á vez. Los padres la esconden en la torre. & Salir de la torre. \\
\hline $\mathbf{1 0}$ & $\begin{array}{l}\text { Tiene visiones y posesiones. Aprende a no contar a nadie sus visiones. Conoce } \\
\text { el mundo y la danza a través de lo que le cuenta Salomé. Le encanta la danza } \\
\text { de Salomé. Aprende con el padre a hacer perfumes y con la madre la tradición } \\
\text { mirrófora. }\end{array}$ & $\begin{array}{l}\text { Obtener la curación de sus } \\
\text { posesiones y conocer el } \\
\text { mundo. }\end{array}$ \\
\hline $\mathbf{1 4}$ & $\begin{array}{l}\text { Sale de la torre en el día del entierro de la madre. De regreso a casa, se pierde } \\
\text { por las calles de Magdala y entra en un prostíbulo pensando que es un } \\
\text { templo. Tiene su primer orgasmo (aunque siga siendo virgen). }\end{array}$ & $\begin{array}{l}\text { Su padre sube a la torre con el objetivo de exorcizarla. Lee las sagradas } \\
\text { escrituras, pero la Magdalena permanece poseída. El padre siente deseo por } \\
\text { ella, y para no violarla, se lanza desde la torre, suicidándose. Ella hereda la } \\
\text { casa del padre, sigue teniendo posesiones. Unas veces se auto-mutila; en }\end{array}$ \\
\hline
\end{tabular}




\begin{tabular}{|c|c|c|}
\hline & otras, encuentra el placer en los libros. & \\
\hline 25 & Se entrega a los placeres de la carne a cambio de sabiduría. & Obtener conocimiento. \\
\hline 30 & $\begin{array}{l}\text { Va a una boda y transforma agua en vino, en alusión al pasaje bíblico: Una } \\
\text { boda en Caná de Galilea (Jn 2: 1-11). La actriz/dramaturga transgredió el } \\
\text { pasaje bíblico, poniendo a María Magdalena como autora del milagro. La } \\
\text { Magdalena escucha comentarios con respecto a Juan Bautista. }\end{array}$ & $\begin{array}{l}\text { Saber quién es el tal } \\
\text { "mesías" del que Juan } \\
\text { Bautista habla. }\end{array}$ \\
\hline 31 & Descubre la sabiduría de la oralidad. Da su cuerpo a cambio de historias. & Obtener conocimiento. \\
\hline 33 & $\begin{array}{l}\text { Guardias romanos tienen noticia de su voluptuosidad y la buscan cada vez } \\
\text { con más frecuencia. Sus visiones de la infancia vuelven, y ella ve el infierno en } \\
\text { su cama, y decide que no lo quiere hacer más. Un centurión romano desea } \\
\text { que ella satisfaga a toda una tropa. Ella se niega, los hombres le lanzan } \\
\text { piedras. En este momento, ella cuestiona la maldición que pesa sobre todas } \\
\text { las mujeres y compara a la mujer con la serpiente, ya que ambas fueron las } \\
\text { que mostraron el conocimiento a los hombres (a través de la tentación de Eva } \\
\text { por la propia Serpiente). Jesús llega y la defiende. }\end{array}$ & $\begin{array}{l}\text { Dejar de entregar su cuerpo } \\
\text { a uno cualquiera. }\end{array}$ \\
\hline 33 & $\begin{array}{l}\text { Va a dar las gracias a Jesús a casa de un fariseo, y le lleva un perfume muy } \\
\text { caro. }\end{array}$ & $\begin{array}{l}\text { Agradecer a Jesús. Pedirle } \\
\text { que la libere del demonio. }\end{array}$ \\
\hline 33 & Va detrás de Jesús y le acompaña, llegando incluso a profetizar. & Seguir a Jesús. \\
\hline 33 & $\begin{array}{l}\text { Presencia la traición de Judas. Va a hablar con Poncio Pilatos. Dibuja un plan } \\
\text { para huir con su maestro y con los demás discípulos. }\end{array}$ & Salvar a Jesús. \\
\hline 33 & $\begin{array}{l}\text { Presencia la vía crucis. Muere su maestro. Al día siguiente va al túmulo y } \\
\text { encuentra la tumba vacía. Ve al resucitado que le manda que anuncie la } \\
\text { resurrección a los demás apóstoles. Comprende su misión en el mundo. }\end{array}$ & $\begin{array}{l}\text { Anunciar la doctrina de } \\
\text { Jesús y ser escuchada. }\end{array}$ \\
\hline
\end{tabular}

Fuente: Lucas (2016).

A partir de este ejercicio, en la escena creada a partir de improvisaciones sobre el momento en que María Magdalena sale por primera vez de la torre y ve la ciudad de Magdala, la actriz/dramaturga se cuestionó sobre los padres de María Magdalena e hizo la siguiente asociación: La Magdalena había estado presa en la torre a causa de sus padres, desde que vio al demonio y a un ángel cuando era apenas una niña (porque veía más de lo que veían los demás). Pero cuando su madre muere, ella, que pertenece a una familia de mirróforas, tiene que salir de casa para ungir el cuerpo de la propia madre. Luego se ha definido que el momento en que María Magdalena conocería por fin Magdala sería cuando va al entierro de su madre:

NARRADORA: Los padres de María murieron un día. Fue con el padre con quien aprendió a preparar aceites y perfumes. Pero fue de la madre de quien heredó las tradiciones embalsamadoras, oficio reservado a las mujeres que consistía en ungir los cuerpos con ungüentos funerarios para prepararlos para la morada de los muertos. Aquellos perfumes eran sagrados. Y parecía que se cuidaba más el cuerpo de los muertos que el cuerpo de los vivos. El cuerpo de un muerto precisaba ser preparado para pasar al otro lado, pleno, libre. A los catorce años, Magdalena usó ese conocimiento para ungir el cuerpo de su propia madre (Pausa) (LUCAS, 2012, p. 69). 
De la misma forma, a partir de la situación del contraste del deseo como algo sagrado y no profano, así como la lectura del placer como una dádiva de Dios, se creó el siguiente texto, que da continuidad a la escena anterior. María Magdalena se perdería y encontraría un templo que, en realidad, sería un prostíbulo:

\begin{abstract}
NARRADORA: Fue el día del entierro cuando ella vio la ciudad de Magdala por primera vez. En la vuelta a casa, mientras el padre compraba esencias, María se perdió y caminó por las calles siguiendo el olor de un perfume desconocido hasta atravesar una puerta de bronce. Caminó por un pasillo oscuro, llegando a una alcoba. Había cuerpos que danzaban con frenesí, bañados en sudor, perfumes y olor de esperma. La voluptuosidad de ángeles y demonios poseyendo cuerpos la hizo sentirse dentro de los templos descritos por Salomé. Magdalena se sintió ebria y con unas ganas incontenibles de bailar. Se dejó llevar por aquel soplo y en giros infinitos sus vestidos empezaron a caer. $Y$ como si volase en aquel espacio sagrado, su "cuerpo en fuego" explotó en un orgasmo. (La actriz baila, se vuelve loca, caen trozos de sus vestidos o sus vestidos enteros.).

MAGDALENA: No vi nada más. Cuando me desperté, sentí mi cuerpo desnudo arrastrado por el pasillo. Mi padre me agarraba por el pelo, mientras yo veía el mundo desde la perspectiva de un gusano: llenos de tierra en todos los orificios. Pero no fue esa la imagen que guardé en mis recuerdos. La imagen que se quedó en mi alma fue la de aquel templo, donde sentí la danza y el gozo por primera vez en mi cuerpo. Lo que yo no sabía es que aquel templo no era sagrado, sino consagrado por las prostitutas de la ciudad de Magdala (LUCAS, 2012, p. 70).
\end{abstract}

Por tanto, María Magdalena seguiría presa en la torre. Es decir, saldría para ungir el cuerpo de la madre muerta y volvería a su encierro. Para sacar al personaje de la torre, se propuso la siguiente solución: ya que la Magdalena estaba poseída, en uno de sus arrebatos, el padre, que conocía la Torah (libro sagrado de los judíos), subiría a la torre con el objeto de exorcizarla, leería antiguas escrituras, sentiría atracción por la propia hija y, para no violarla, se mataría. Así, la actriz/dramaturga también justificaba el conocimiento que María Magdalena podría tener de las escrituras, aunque fuera mujer:

MAGDALENA: Una noche, mi padre subió a la torre dispuesto a vencer al demonio que me poseía. Leyó antiguas escrituras. Sentí mi cuerpo retorcerse y nacer dentro de mí el deleite que hacía que mi cuerpo girara y mis vestidos cayeran. Solo me acuerdo de bailar. Cuando desperté, la ventana de la torre estaba rota y abajo estaba mi padre. Muerto. La vieja esclava me contó que él, horrorizado por el deseo que sentía, se lanzó por la ventana de la torre antes que desflorarme (LUCAS, 2012, p. 70).

Se crearon más textos, entre ellos, una supuesta respuesta de María Magdalena al episodio de la lapidación, trabajando con la idea de que la Magdalena es la mujer sorprendida en adulterio, en alusión al pasaje bíblico del Evangelio de San Juan (BIBLIA, Juan, 8, 1- 11, 2008b):

MAGDALENA: iApedreadme! Sofocad mis gritos, suprimid mis pasos, perfumes y vestidos. Esconded a vuestras mujeres y golpeadme. "La Impura". Pero no olviden que para los 
hombres, todas nosotras somos impuras. Por la sangre que sale de entre nuestras piernas. Por los vestidos que despiertan el deseo dormido. ¡Por nuestra delicadeza que enseña otro Dios y no ese dios de sangre, de infinitas batallas y sufrimiento! iSomos impuras porque les damos hijos! Según vuestra escritura: si damos a luz a un varón permanecemos "impuras" siete días más treinta y tres y si damos a luz a una niña, seremos "impuras" quince más sesenta y seis días. Aún deberemos sacrificar animales para purificarnos de la naturaleza de procrear. ¿No ha sido vuestro Dios quien dijo: "Tened muchos, muchos hijos; poblad el mundo"? ¿Cómo ese mismo Dios llama inmunda a aquella que llena la tierra con vuestros hijos? Los hombres inventan un Dios que reniega de nosotras. Deberíamos ser vuestras compañeras. Pero vosotros nos aprisionáis con ignorancia, silencio y claustro. ¿Por qué la mujer y la serpiente son malditas si ellas mostraron el conocimiento al hombre? ¡Apedreadme! ¡Apedreen a la que no usa velo! iQue no tiene hijos! Que anda sola y expresa su voluntad. ¡Apedreen a la "pecadora"! Mañana vosotros apedreareis a vuestras hijas y a las hijas de vuestras hijas (LUCAS, 2012, p. 69-75).

A partir del contacto con las distintas tradiciones, fuentes y visiones con respecto al personaje, y a todo aquello que él representa, la actriz/dramaturga creó el siguiente texto que juzgó oportuno agregarlo al final de la creación dramatúrgica:

Yo soy aquella que acoge la muerte y baila con ella, contemplando su otro rostro. Me critican y me alaban con la misma convicción. Mis vestidos son páginas satinadas de textos prohibidos. Abrazo la muerte. Estoy en las calles.

Soy incomprendida; Bilingüe;

Fugitiva.

Rasgo mis vestiduras de papel y en mi desnudez se ve el alma del mundo. Aquello que los profetas dijeron, un día se convertirá en libro y llamarán verdad. La verdad de las calles ocupará las paredes de las bibliotecas en un trabajo manual que tardará siglos de lucha y persecución. Escribo mi experiencia. Mi evangelio. En años de historia, el mensaje de este pueblo marginal se va a difundir como ecos que recorren catacumbas y se expandirá por el mundo. iY todavía, los hombres seguirán buscando la verdad! Padre, perdónalos porque no saben lo que hacen (LUCAS, 2012, p. 78-79).

El texto producido hasta el momento fue perfilado e luego pasó a ser leído a una serie profesionales del teatro y personas ajenas al mundo teatral. Al final del octavo mes se puso fin a la dramaturgia. El guión inicial sufrió alteraciones hasta su finalización. La Tabla 2 resume de forma esquemática todas las actividades realizadas durante el experimento:

Tabla 02 - Esquema de las actividades realizadas durante el experimento Lo profano y lo sagrado en la figura femenina.

\begin{tabular}{|c|l|}
\hline Mes & \multicolumn{1}{c|}{ Actividades realizadas en Sevilla - España } \\
\hline 1.Febrero & Estudio del personaje de María Magdalena. \\
\hline \multirow{2}{*}{ 2.Marzo } & $\begin{array}{l}\text { Estudio del personaje de María Magdalena. } \\
\text { Selección de situaciones sacras y profanas de María Magdalena. } \\
\end{array}$ \\
& $\begin{array}{l}\text { Planteamiento de los posibles objetivos del personaje. } \\
\text { Catálogo de posibles estímulos para la creación. }\end{array}$ \\
\hline
\end{tabular}




\begin{tabular}{|c|l|}
\hline 3.Abril & $\begin{array}{l}\text { Experimentaciones prácticas. } \\
\text { Trabajo de campo en la Semana Santa de Sevilla. }\end{array}$ \\
\hline 4.Mayo & $\begin{array}{l}\text { Experimentaciones prácticas. } \\
\text { Visita y registro fotográfico a la Parroise Madeleine (Paris). }\end{array}$ \\
\hline 5.Junio & $\begin{array}{l}\text { Experimentaciones prácticas. } \\
\text { Primer esbozo de guión y definiciones objetivas en la dramaturgia. } \\
\text { Presentación de actuación/ performance/demostración técnica. }\end{array}$ \\
\hline Mes & \multicolumn{1}{c|}{ Actividades realizadas en Porto Alegre y São Paulo (Brasil) } \\
\hline 6.Julio & $\begin{array}{l}\text { Perfeccionamiento del guión. } \\
\text { Se profundiza en la historia personal de María Magdalena. } \\
\text { Se fragmenta temporalmente el texto. }\end{array}$ \\
\hline 7.Agosto & $\begin{array}{l}\text { Orientación dramatúrgica a cargo de Luiz Valcazaras (São Paulo). } \\
\text { Realización de ejercicios de Dramaturgia con Luiz Valcazaras (São Paulo). } \\
\text { Se distinguen las narraciones en primera y tercera persona. } \\
\text { Se enriquecen los parlamentos de María Magdalena. } \\
\text { Se eliminan parlamentos de otros personajes. } \\
\text { Cortes y alteraciones en el guión. } \\
\text { Se hacen lecturas del texto a diferentes personas. }\end{array}$ \\
\hline 8.Septiembre & $\begin{array}{l}\text { Perfeccionamiento de detalles finales. } \\
\text { Finalización de la dramaturgia. } \\
\text { Correcciones en el texto (versión en español). }\end{array}$ \\
\hline
\end{tabular}

Fuente: Lucas (2016).

\section{RESULTADOS FINALES DEL EXPERIMENTO}

La dramaturgia, con un lenguaje poético e intimista, se expresa tanto en tercera como en primera persona: La Narradora contando la historia de María Magdalena, María Magdalena reaccionando y confesando su propia historia. En algunos momentos hay pequeñas interferencias de otros personajes como Salomé y Juan Bautista. Además, figuran en el texto los personajes Padre y Madre de María Magdalena, Jesucristo, un Centurión Romano, dos Ángeles e un Demónio. Se propone que la obra sea interpretada por una sola actriz que pueda presentar a todos los personajes que se nombran, y para ello deberá modular acciones y voces, así como enfoques corporales, de modo que interprete de forma diferenciada principalmente las figuras de la Magdalena y de la Narradora. A finales de 2012 el texto fue publicado en Dramaturgia de Iberescena: Antología (México), representando a Brasil.

\section{CONCLUSIONES}

A través del experimento se ha podido configurar un trabajo teatral y literario que contribuyó en la formación artístico-investigativa de la actriz/dramaturga. El registro de sus etapas permitió una evaluación constante, de forma que la práctica contribuyó a la producción de 
conocimiento en el campo de las Artes Escénicas. La inmersión investigativa en torno al personaje, las situaciones exploradas, oriundas de tradiciones evangélicas, eclesiásticas, legendarias y situaciones fruto de la imaginación de la actriz/dramaturga, incorporadas a las experimentaciones con distintos estímulos, permitieron una creación dramatúrgica que recría poéticamente la trayectoria de la protagonista, ficcionalizando algunas de sus tradiciones europeas.

Este estudio demuestra que el proceso de creación dramatúrgica del actor se configura como una forma alternativa a la teoría y práctica teatrales, que permite al actor/dramaturgo dar voz a sus creaciones sin la necesidad de un texto previamente establecido. Para ello, el actor/dramaturgo debe tener claro su enfoque, apoyarse en una sólida investigación, valer se de técnicas apropiadas y elegir un personaje complejo y atractivo como para comunicarse con el público.

\section{REFERENCIAS}

BARBAS, Helena. Madalena: história e mito. Lisboa: Ésquilo, 2008.

BIBLIA. Evangelio de Mateo. In: BIBLIA. Español. Biblia de nuestro pueblo: Biblia del peregrinoAmérica Latina. Bilbao: Mensajero, 2008a. p. 1507-1576.

BIBLIA. Evangelio de Juan. In: BIBLIA. Español. Biblia de nuestro pueblo: Biblia del peregrinoAmérica Latina. Bilbao: Mensajero, 2008b. p. 1673-1691.

BIBLIA. Evangelio de Marcos. In: BIBLIA. Español. Biblia de nuestro pueblo: Biblia del peregrinoAmérica Latina. Bilbao: Mensajero, 2008c. p. 1577- 1613.

BROOK, Peter. A porta aberta. Rio de Janeiro: Civilização Brasileira, 2000.

DUBY, Georges. Damas del siglo XII: Eloísa, Leonor, Iseo y algunas otras. Madrid: Alianza, 1995.

ELIADE, Mircea. Lo sagrado y lo profano. Barcelona: Paidós Orientalia, 1998.

LELOUP, Jean-Yves. 0 romance de Maria Madalena: uma mulher incomparável. Campinas: Verus, 2004.

LUCAS, Elisa Martins. La dama de los evangelios. In: Dramaturgia de iberescena: antología. México: Paso de Gato, 2012. p. 63-79. 
LUCAS, Elisa Martins. La dama de los Evangelios. Sevilla: IBERESCENA, 2011. Disponible en: http://www.iberescena.org/Files/Dramaturgias/1319458046-

Texto.La\%20Dama\%20de\%20los\%20Evangelios.pdf. Consultado em: 23 jul. 2019.

LUCAS, Elisa Martins. Lo Profano y lo Sagrado en el proceso de creación dramatúrgica del actor a partir del personaje de María Magdalena: Interrelación entre teoría y praxis escénica. Sevilla: Universidad de Sevilla, 2015. Tesis (Doctorado en Ciencias del Espectáculo) - Programa de Doctorado en Ciencias del Espectáculo, Facultad de Filología, Universidad de Sevilla, Sevilla, 2016. (Tesis no publicada).

MAGNO, Gregorio. Obras de San Gregorio Magno: Regla pastoral; Homilías sobre la profecía de Ezequiel; Cuarenta homelias sobre los Evangelios. Madrid: Biblioteca de Autores Cristianos, 1958.

PANISSON, Luciane. A poética do sensorial: procedimentos de composição da cena imagética. 2016. Dissertação (Mestrado em Artes Cênicas) - Instituto de Artes, Universidade Federal do Rio Grande do Sul, Porto Alegre, 2016. Disponible en: http://hdl.handle.net/10183/148007. Consultado em: 23 jul. 2019.

PAVIS, Patrice. Análise dos espetáculos: teatro, dança, dança-teatro, cinema. São Paulo: Perspectiva, 2003.

WILDE, Oscar. Salomé. São Paulo: Martin Claret, 2003. 